\title{
Circulating tumor cells in non-metastatic triple-negative breast cancer
}

\author{
Mandar Karhade $\cdot$ Carolyn Hall • Priyankana Mishra • \\ Amber Anderson · Henry Kuerer • Isabelle Bedrosian • \\ Savitri Krishnamurthy $\cdot$ Anthony Lucci
}

Received: 25 April 2014/ Accepted: 11 August 2014/Published online: 28 August 2014

(C) The Author(s) 2014. This article is published with open access at Springerlink.com

\begin{abstract}
Circulating tumor cells (CTCs) can be identified in approximately $25 \%$ of stage I-III breast cancer patients; CTCs presence is a predictor of poor outcome in metastatic breast cancer, but little is known regarding the prognostic significance of CTCs in non-metastatic triplenegative breast cancer (TNBC) patients. The aim of this study was to determine whether CTCs predict worse outcome in non-metastatic TNBC patients. We evaluated CTCs in 113 patients with stages I-III TNBC at the time of definitive surgery. CTCs were assessed using the CellSearch System $^{\circledR}$. Progression-free and overall survival were defined as time elapsed between date of diagnosis and either date of clinical disease progression, death, or last follow-up. Log-rank test and Cox regression analysis were used to determine associations of CTCs with progressionfree and overall survival. The median follow-up was 40 months. CTCs were identified in 23/113 (20\%) of patients. No primary tumor characteristic or lymph node status predicted the presence of CTCs. The identification of $\geq 2$ CTCs predicted shorter progression-free (log rank $P \leq 0.001$; hazard ratio $8.30,95 \%$ CI 2.61-26.37) and overall survival (log rank $P=0.0004$; hazard ratio 7.19, $95 \%$ CI 1.98-26.06) versus survival for patients with $<2$ CTCs. Two or more CTCs predict shorter progression-free and overall survival in TNBC patients. Larger studies are
\end{abstract}

\footnotetext{
M. Karhade - C. Hall · P. Mishra - A. Anderson - H. Kuerer .

I. Bedrosian - A. Lucci $(\bowtie)$

Department of Surgical Oncology, Unit 0444, The University of

Texas MD Anderson Cancer Center, 1515 Holcombe Blvd,

Houston, TX 77030, USA

e-mail: alucci@mdanderson.org

S. Krishnamurthy

Departments of Pathology, The University of Texas MD

Anderson Cancer Center, Houston, TX, USA
}

needed to determine whether CTC assessment provides beneficial information that could be used in stratifying TNBC patients at increased risk for disease progression. Finally, CTCs characterization could facilitate the development of novel treatment approaches for TNBC.

Keywords Circulating tumor cells - Triple-negative breast cancer - Non-metastatic breast cancer - Progressionfree survival · Overall survival

\section{Introduction}

Breast cancer, the most frequently diagnosed cancer and the leading cause of cancer deaths among women, is a heterogeneous disease that is classified and subtyped using clinical and pathologic features including patient age and tumor size, axillary node involvement, histologic grade, estrogen (ER) and progesterone (PR) hormone receptor status, and human epidermal growth factor receptor 2 (HER2) amplification. ER and/or PR receptors are expressed in a majority of breast cancers, and HER2 is amplified in approximately $20 \%$ of cases [1]. Triple-negative breast cancer (TNBC) is an aggressive phenotype comprising 10-20\% of all breast cancers [1]. Triple-negative breast tumors lack ER, PR, and HER2 expression. Because of the absence of ER and HER2 expression and the aggressive nature of TNBC, effective management of TNBC patients remains a challenge in the clinic. Triplenegative patients are typically treated sequentially with a combination of chemotherapy, surgery, and radiation. These tumors respond favorably to neoadjuvant chemotherapy (NACT), and TNBC patients are more likely to achieve pathologic complete response (pCR) following completion of NACT than are breast cancer patients with 
non-triple-negative tumors [2, 3]. Although pCR predicted excellent survival regardless of tumor receptor status, TNBC patients with residual disease following NACT experience significantly shorter disease-free and overall survival than patients with non-triple-negative tumors and residual disease after NACT [4-6].

Overall, numerous published studies have shown that TNBC patients exhibit significantly shorter overall survival than do patients with other breast cancer subtypes, independent of clinicopatholigic characteristics such as tumor size/grade and lymph node status [2, 4, 6]. Interestingly, TNBC patients typically recur within the first 3 years following treatment $[3,4,6]$ with a propensity toward visceral and cerebral (not bone or lymph node) metastases [7, 8].

Distant metastasis remains the primary cause of death for breast cancer patients. Historically, most clinical research efforts have focused on the prognostic significance of micrometastatic spread of cancer cells to lymph nodes; to date, lymph node positivity is the most powerful predictor of disease recurrence in patients with non-metastatic breast cancer. However, a significant number of patients with lymph node-negative disease recur, whereas almost a third of patients with lymph node-positive disease do not have a recurrence within 10 years following treatment $[9$, 10]. Over the past decade, improved enrichment and detection techniques have enabled clinical researchers to pursue studies to identify and determine the prognostic significance of occult micrometastatic cells within the blood [circulating tumor cells (CTCs) ]. Although the mechanisms mediating micrometastatic dissemination to the bloodstream are unknown, we know that these rare cells typically remain undetected by standard pathologic assessments and imaging technologies. CTCs are heterogeneous populations of cells with varying viability, dormancy, biomarker expression, and metastatic capabilities. This heterogeneity makes both detecting CTCs and determining their clinical importance a challenge. Originally, circulating tumor cell studies focused on identification and significance in the metastatic setting. However, since metastatic patients represent only a small percentage of breast cancer cases, many research groups are investigating the prognostic significance of CTCs in the non-metastatic setting. In theory, routine circulating tumor cell analyses have the potential of providing "real-time" assessments of occult micrometastatic dissemination and recurrence risk throughout treatment and during routine follow-up visits.

The Cell Search System ${ }^{\circledR}$ (Janssen, Raritan, NJ) can detect as few as one CTC per $7.5 \mathrm{~mL}$ of peripheral blood and to date remains the only U.S. Food and Drug Administration-approved methodology for CTC detection in patients with metastatic breast, colorectal, and prostate cancers. Using this methodology, the presence of five or more CTCs per $7.5 \mathrm{~mL}$ blood prior to administration of systemic treatment has been shown to be an independent predictor of shortened progression-free and overall survival in metastatic breast cancer [11]. Data are emerging regarding the predictive significance of CTCs in patients with non-metastatic breast cancer. Results from the French REMAGUS trial [12], the German SUCCESS-A trial [13], and a recent report from our group [14] indicate that the identification of one or more circulating tumor cell predicted progression-free and overall survival in patients with non-metastatic breast cancer. However, no data have been published about the prognostic significance of circulating tumor cell identification specifically in patients with nonmetastatic TNBC.

We hypothesized that the presence of CTCs would independently predict shorter progression-free and overall survival in patients with non-metastatic TNBC, regardless of axillary lymph node status or other primary tumor characteristics such as tumor size and grade. If circulating tumor cell presence was to add to the currently available prognostic information, this would help identify TNBC patients who remain at high risk for disease progression and death. To test our hypothesis, we evaluated CTCs in patients with stages I-III TNBC at the time of definitive surgery.

\section{Materials and methods}

\section{Patients}

This study included 113 patients with stages I-III TNBC who underwent surgery for their primary tumor between February 2005 and February 2012. All eligible TNBC patients with non-metastatic breast cancer seen by Drs. Lucci, Kuerer, and Bedrosian at The University of Texas MD Anderson Cancer Center were given an opportunity to enroll in this study. The institutional review board at The University of Texas MD Anderson Cancer Center approved this prospective study (04-0698; PI: A.L.), which included circulating tumor cell assessment at a single time point just prior to primary surgery for breast cancer. Patients with bilateral breast cancer or any other malignancy within 5 years of diagnosis of the current cancer were ineligible for this study.

We obtained informed written consent from all patients prior to blood collection. Enrollment was strictly voluntary; patients did not receive a stipend for participating. Individual patient results were blinded from investigators using a random number system as a unique patient identifier.

Staging and classification

TNM staging [primary tumor $(\mathrm{T})$, regional nodes $(\mathrm{N})$, distant metastases $(\mathrm{M})]$ and tumor grade were designated 
according to the criteria of the American Joint Commission on Cancer (AJCC) [15] and Black's nuclear grading system [16], respectively. Clinical stage was defined as the TNM stage determined at the time of the first diagnostic procedure confirming the invasive component of the tumor. Tumor sections were immunostained for ER, PR, and HER2 using previously published procedures [17]. Primary breast tumors that expressed nuclear staining in $\geq 1 \%$ of tumor cells were considered positive for ER and/or PR expression. Immunostaining results for HER2 were scored as positive when $>10 \%$ of the tumor cells had membranous staining or when fluorescence in situ hybridization (FISH) for HER2 gene amplification using the Abbott PathVysion HER2 DNA probe kit (Abbott Laboratories, Abbott Park, Ill) yielded a HER2/CEP17 ratio of $>2.2$. TNBC was defined by absence of ER and PR expression and the absence of HER-2 immunostaining and/or gene amplification in the primary tumor. Tumors were immunostained and considered Ki-67 positive when $\geq 35 \%$ of tumor cells exhibited Ki-67 staining.

Isolation, staining, and enumeration of circulating tumor cells

Peripheral blood $(7.5 \mathrm{~mL})$ was collected at the time of primary tumor surgery but prior to any surgical manipulation of the primary tumor. Circulating tumor cell status was determined using the CellSearch System ${ }^{\circledR}$ (Janssen Diagnostics, LLC) within $72 \mathrm{~h}$ of blood collection. This semi-automated technology uses antibody-coated magnetic beads to enrich blood samples for cells expressing the epithelial-cell-adhesion molecule, labels the nuclei of these enriched cells with the fluorescent dye 4,2-diamidino-2-phenylindole dihydrochloride, and stains the enriched cells using a combination of CK 8,18,19, and CD45 fluorescent antibodies. A semiautomated fluorescence-based microscope system was

Table 1 Patient demographics and characteristics

\begin{tabular}{|c|c|c|c|c|}
\hline \multirow[t]{2}{*}{ Variables } & \multirow{2}{*}{$\begin{array}{l}\text { Overall cohort } \\
\text { Number of subjects (\%) }\end{array}$} & \multicolumn{2}{|c|}{1 or more circulating tumor cells } & \multirow[t]{2}{*}{$P$ value (Chi squared test $P$ value) } \\
\hline & & Positive $(\%)$ & Negative $(\%)$ & \\
\hline Total subjects & 113 & $23(20 \%)$ & $71(80 \%)$ & $P=0.54$ \\
\hline Mean age (years) & 54 (range $28-80$ ) & 55 & 54 & \\
\hline Median follow-up (months) & 40 (range 6-88) & 36 & 40 & \\
\hline Tumor size & & & & $P=0.61^{\wedge}$ \\
\hline$<2 \mathrm{~cm}(\mathrm{~T} 1)$ & $30(27 \%)$ & $5(22 \%)$ & $19(27 \%)$ & \\
\hline $2-5 \mathrm{~cm}(\mathrm{~T} 2)$ & $48(42 \%)$ & $8(35 \%)$ & $30(49 \%)$ & \\
\hline$>5 \mathrm{~cm}(\mathrm{~T} 3)$ & $12(11 \%)$ & $3(13 \%)$ & $6(9 \%)$ & \\
\hline Skin/chest wall infiltration (T4) & $23(21 \%)$ & $7(30 \%)$ & $15(21 \%)$ & \\
\hline Pathologic nodal status & & & & $P=0.55$ \\
\hline Node negative & $51(45 \%)$ & $10(34 \%)$ & $34(48 \%)$ & \\
\hline 1-3 Lymph nodes & $39(35 \%)$ & $6(26 \%)$ & $23(32 \%)$ & \\
\hline$>3$ lymph nodes & $23(20 \%)$ & $7(30 \%)$ & $14(20 \%)$ & \\
\hline Histologic tumor grade & & & & $P=0.52^{\#}$ \\
\hline Low grade (Grade 1) & $4(4 \%)$ & $3(13 \%)$ & $1(1 \%)$ & \\
\hline Intermediate grade (Grade 2) & $15(13 \%)$ & $2(9 \%)$ & $10(14 \%)$ & \\
\hline High grade (Grade 3 ) & $92(81 \%)$ & $18(78 \%)$ & $58(82 \%)$ & \\
\hline Missing & $2(2 \%)$ & $0(1 \%)$ & $2(2 \%)$ & \\
\hline $\mathrm{Ki} 67<35 \%$ & $16(31 \%)$ & $4(26 \%)$ & $10(29 \%)$ & $P=0.62$ \\
\hline $\mathrm{Ki} 67>35 \%$ & $36(69 \%)$ & $7(64 \%)$ & $25(71 \%)$ & \\
\hline Missing $^{\mathrm{a}}$ & $40(50 \%)$ & $9(47 \%)$ & $31(51 \%)$ & \\
\hline Neoadjuvant chemotherapy & $58(51 \%)$ & $13(57 \%)$ & $35(43 \%)$ & $P=0.55$ \\
\hline Pre-menopausal women & $30(28 \%)$ & $6(26 \%)$ & $17(25 \%)$ & $P=0.92$ \\
\hline Missing & $5(6 \%)$ & $1(5 \%)$ & $4(7 \%)$ & \\
\hline
\end{tabular}

${ }^{\text {a }}$ Ki67 not routinely performed in all breast cancer patients

\# For High grade versus Low grade

${ }^{\wedge}$ For Tumor size $>2 \mathrm{~cm}$ versus 2 or less 
employed to identify CTCs; nucleated cells were positive for CK and negative for CD45, as described previously [11]. All results were reviewed by a qualified laboratory technician who was blinded to all patient data. Given the prognostic significance of one or more CTCs in patients with nonmetastatic breast cancer, a cutoff of one or more CTCs was considered positive in this study.

\section{Statistical analyses}

REMARK biomarker guidelines for reporting were used in the present study [18]. We used Chi-square or Fisher's exact tests to determine associations between presence of CTCs and primary tumor characteristics. Fisher's exact test was applied when one or more cells with expected value was less than 5. Progression-free and overall survival were defined as time elapsed between date of diagnosis and either the date of clinical disease progression, death, or the last follow-up. Log-rank tests were used to detect significant differences between groups. Kaplan-Meier curves were derived using STATA/IC 11.2 software (StataCorp, College Station, TX) for comparison of groups defined by different circulating tumor cell counts. The Cox proportional hazards regression model was used to determine univariate hazard ratios for progression-free and overall survival. $P$ values were two tailed, and values $<0.05$ were considered statistically significant.

\section{Results}

\section{Patient Characteristics}

A total of 113 patients with TNBC were enrolled in this study, and their demographic data and characteristics are reported in Table 1. The mean patient age was 54 years, and median follow-up was 40 months. Thirty patients (27\%) had T1 stage tumors, 53 patients (53\%) had T2/T3, and 23 patients $(21 \%)$ had infiltration of the chest wall at the time of presentation. Fifty-one patients $(45 \%)$ had node-negative disease, 39 patients $(35 \%)$ had $1-3$ positive lymph nodes, and 23 patients $(20 \%)$ had more than 3 positive lymph nodes at the time of surgery. Grade 3 disease was observed in 92 patients $(81 \%)$, and 58 patients $(51 \%)$ received NACT prior the time of blood draw for circulating tumor cell analysis. Seventy-one patients (63\%) had no CTCs, 23 patients $(20 \%)$ were positive for one or more CTCs, 6 patients $(5 \%)$ were positive for two or more CTCs, and 5 patients (4\%) had three or more CTCs (Tables 2, 3).

Circulating tumor cells and progression-free survival

Patients with one or more circulating tumor cell showed decreased progression-free survival than did patients with no CTCs using log-rank test $(P=0.002)$ and Cox proportional

Table 2 Progression-free and overall survival in patients with CTCs

(A) Progression-free survival

\begin{tabular}{|c|c|c|c|c|c|c|}
\hline Variable name & Status & Number & Relapses $(\%)$ & $\begin{array}{l}\text { Relapse free survival } \\
\text { proportion at } 48 \text { months (\%) }\end{array}$ & $95 \%$ C.I. & $\begin{array}{l}P \text { Values by } \\
\text { log-rank test }\end{array}$ \\
\hline \multicolumn{7}{|l|}{ By number of circulating tumor cells } \\
\hline \multirow[t]{2}{*}{ One or more circulating tumor cells } & + & 23 & $9 / 23(39 \%)$ & 61 & $38-77$ & \multirow[t]{2}{*}{0.002} \\
\hline & - & 71 & $10 / 71(14 \%)$ & 84 & $72-92$ & \\
\hline \multirow[t]{2}{*}{ Two or more circulating tumor cells } & + & 6 & $4 / 6(67 \%)$ & 33 & $5-68$ & \multirow[t]{2}{*}{$\leq 0.0001$} \\
\hline & - & 88 & $15 / 88(17 \%)$ & 81 & $70-86$ & \\
\hline \multirow[t]{2}{*}{ Three or more circulating tumor cells } & + & 5 & $4 / 5(80 \%)$ & 20 & $1-58$ & \multirow[t]{2}{*}{$\leq 0.0001$} \\
\hline & - & 89 & $15 / 89(17 \%)$ & 81 & $70-89$ & \\
\hline \multicolumn{7}{|l|}{ (B) Overall survival } \\
\hline Variable name & Status & Number & Deaths $(\%)$ & $\begin{array}{l}\text { Overall survival } \\
\text { proportion at } 48 \text { months (\%) }\end{array}$ & $95 \%$ C.I. & $\begin{array}{l}P \text { Values by } \\
\text { log-rank test }\end{array}$ \\
\hline \multicolumn{7}{|l|}{ By number of circulating tumor cells } \\
\hline \multirow[t]{2}{*}{ One or more circulating tumor cells } & + & 23 & $6 / 23(26 \%)$ & 70 & $45-86$ & \multirow[t]{2}{*}{0.09} \\
\hline & - & 71 & $9 / 71(13 \%)$ & 86 & $74-93$ & \\
\hline \multirow[t]{2}{*}{ Two or more circulating tumor cells } & + & 6 & $3 / 6(50 \%)$ & 30 & $1-72$ & \multirow[t]{2}{*}{0.0004} \\
\hline & - & 88 & $12 / 88(14 \%)$ & 85 & $74-91$ & \\
\hline \multirow[t]{2}{*}{ Three or more circulating tumor cells } & + & 5 & $3 / 5(60 \%)$ & 30 & $1-72$ & \multirow[t]{2}{*}{0.0004} \\
\hline & - & 89 & $12 / 89(13 \%)$ & 85 & $74-91$ & \\
\hline
\end{tabular}


Table 3 Cox regression univariate analyses of patient survival according to presence of CTCs

\begin{tabular}{|c|c|c|c|}
\hline & $\begin{array}{l}\text { Hazard } \\
\text { ratio }\end{array}$ & $95 \%$ C.I. & $P$ Value \\
\hline \multicolumn{4}{|l|}{ Progression-free survival } \\
\hline Primary tumor $>2 \mathrm{~cm}$ & 1.82 & $0.62-5.4$ & 0.25 \\
\hline $\begin{array}{l}\text { Pathologic node negative } \\
\text { versus }\end{array}$ & & & 0.005 \\
\hline 1-3 Lymph nodes & 1.62 & $0.55-4.8$ & \\
\hline$>3$ Lymph nodes & 5.18 & $1.87-14.32$ & \\
\hline Histological high grade & 0.67 & $0.25-1.81$ & 0.45 \\
\hline Neoadjuvant chemotherapy & 1.55 & $0.67-3.59$ & 0.30 \\
\hline $\begin{array}{l}\text { One or more circulating tumor } \\
\text { cells }\end{array}$ & 3.93 & $1.55-9.94$ & 0.005 \\
\hline $\begin{array}{l}\text { Two or more circulating tumor } \\
\text { cells }\end{array}$ & 8.30 & $2.61-26.37$ & 0.003 \\
\hline $\begin{array}{l}\text { Three or more circulating } \\
\text { tumor cells }\end{array}$ & 9.89 & $3.14-31.13$ & 0.001 \\
\hline \multicolumn{4}{|l|}{ Overall Survival } \\
\hline Primary tumor $>2 \mathrm{~cm}$ & 1.53 & $0.51-4.59$ & 0.42 \\
\hline $\begin{array}{l}\text { Pathologic node negative } \\
\text { versus }\end{array}$ & & & 0.02 \\
\hline 1-3 Lymph nodes & 1.72 & $0.52-5.64$ & \\
\hline$>3$ Lymph nodes & 5.06 & $1.69-15.18$ & \\
\hline Histological high grade & 0.87 & $0.29-2.62$ & 0.81 \\
\hline Neoadjuvant chemotherapy & 1.58 & $0.64-3.89$ & 0.31 \\
\hline $\begin{array}{l}\text { One or more circulating tumor } \\
\text { cells }\end{array}$ & 2.36 & $0.84-6.65$ & 0.12 \\
\hline $\begin{array}{l}\text { Two or more circulating tumor } \\
\text { cells }\end{array}$ & 7.19 & $1.98-26.06$ & 0.01 \\
\hline $\begin{array}{l}\text { Three or more circulating } \\
\text { tumor cells }\end{array}$ & 7.19 & $1.98-26.06$ & 0.01 \\
\hline
\end{tabular}

hazards analysis (hazard ratio $=3.93 ; 95 \%$ confidence interval $[\mathrm{CI}], 1.55-9.94 ; P=0.005)$. Nine $(39 \%)$ of twenty-three patients with one or more circulating tumor cell relapsed, compared to ten (13\%) of seventy-one patients with no CTCs. The progression-free survival proportion was much lower $(61 \%)$ in patients who had one or more CTCs than in patients who had no CTCs (84\%) (Fig. 1a). As the number of CTCs increased, so did the hazard ratios for disease progression. Patients with two or more CTCs showed decreased progression-free survival than did patients with less than two CTCs using log-rank test $(P \leq 0.0001)$ and Cox proportional hazards model analysis (hazard ratio $=8.30 ; 95 \% \mathrm{CI}, 2.61-26.37 ; P=0.003)$. Four $(67 \%)$ of six patients who had two or more CTCs relapsed compared with fifteen $(17 \%)$ of eighty-eight patients who had less than two CTCs. The progression-free survival was much lower $(33 \%)$ in patients who had two or more CTCs than in patients who had less than two CTCs $(81 \%)$ (Fig. 1b). Patients with three or more CTCs showed
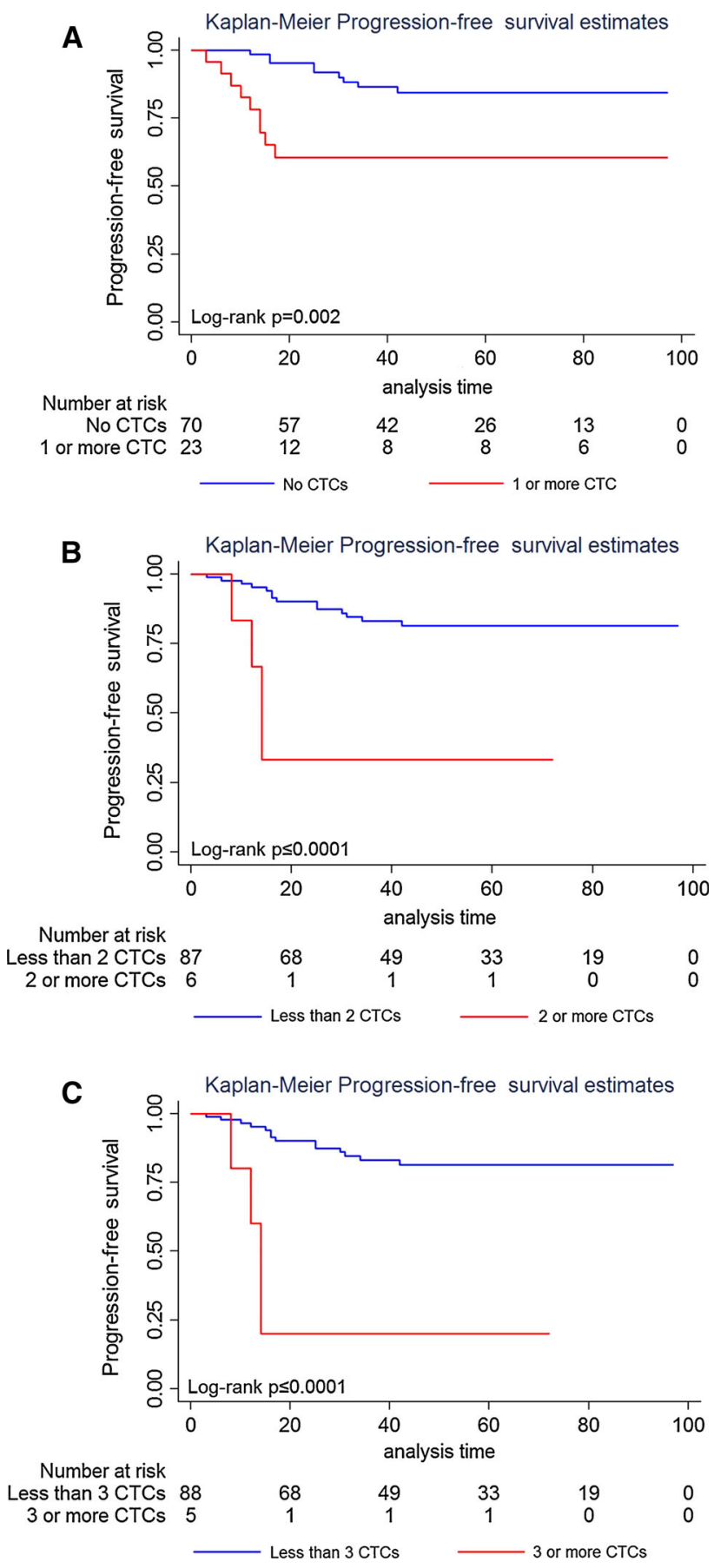

Fig. 1 Probability of progression-free survival. Kaplan-Meier survival estimates of probabilities of progression-free survival according to circulating tumor cells in operable breast cancer. a The probability of progression-free survival in patients with CTC count $\geq 1$ (Hazard ratio 3.93 ; $95 \%$ CI $1.55-9.94$; $\log$ rank $P=0.002$ ) b probability of progression-free survival in patients with CTC count $\geq 2$ (Hazard ratio 8.30; $95 \%$ CI 2.61-26.37; $\log \operatorname{rank} P \leq 0.0001)$ c probability of progression-free survival in patients with CTC count $\geq 3$ (Hazard ratio 9.89; $95 \%$ CI 3.14-31.13; log rank $P \leq 0.0001$ )

decreased progression-free survival than did patients with less than three CTCs using log-rank test $(P \leq 0.0001)$ and Cox proportional hazards analysis (hazard ratio $=9.89$; 
$95 \%$ CI, 3.14-31.13; $P=0.001)$. Four $(80 \%)$ of five patients who had three or more CTCs relapsed compared with fifteen $(17 \%)$ of eighty-nine patients who had less than
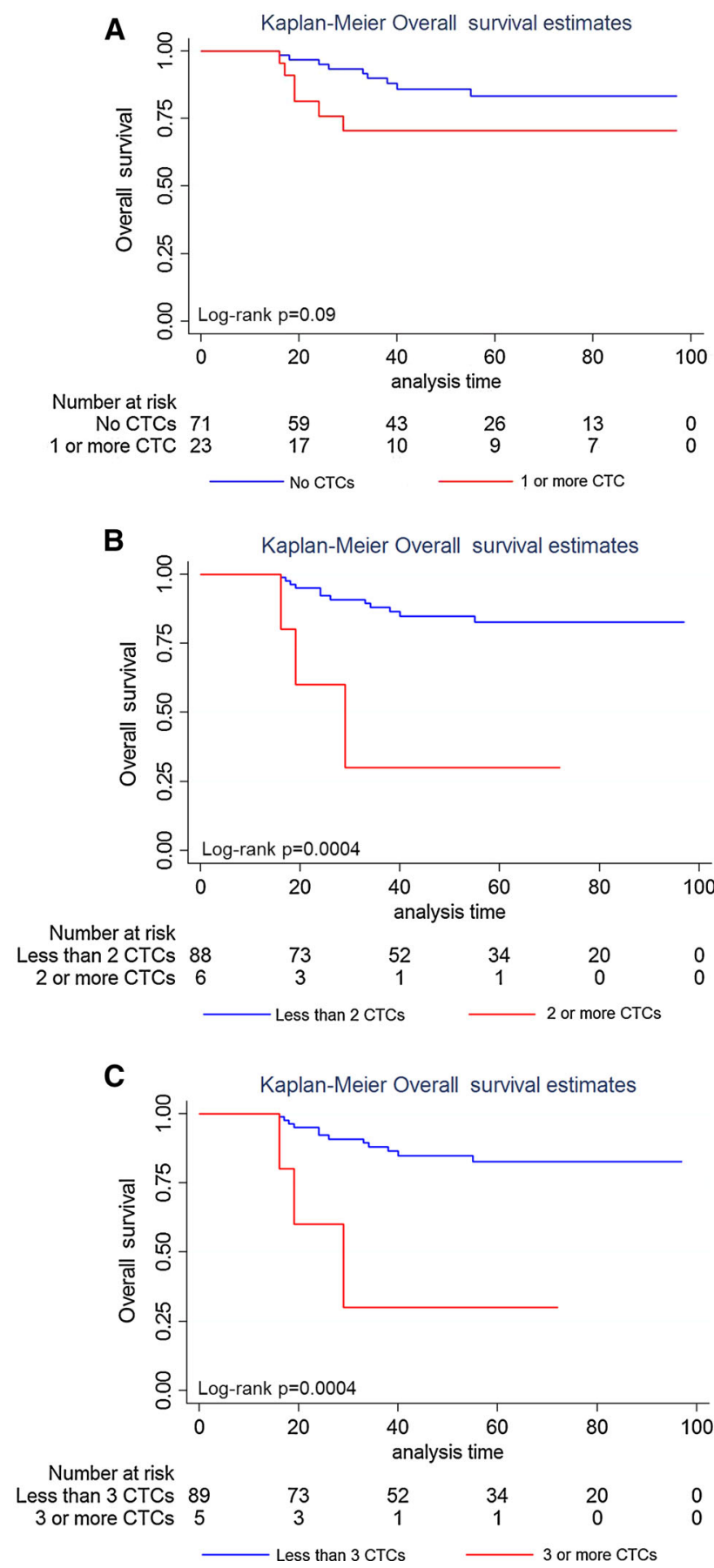

Fig. 2 Probability of overall survival. Kaplan-Meier survival estimates of probabilities of overall survival according to circulating tumor cells in operable breast cancer. a The probability of overall survival in patients with CTC count $\geq 1$ (Hazard ratio 2.36; $95 \%$ CI $0.84-6.65$; $\log$ rank $P=0.09)$ b probability of overall survival in patients with CTC count $\geq 2$ (Hazard ratio 7.19; $95 \%$ CI 1.98-26.06; $\log$ rank $P=0.0004)$ c probability of overall survival in patients with CTC count $\geq 3$ (Hazard ratio 7.19; $95 \%$ CI 1.98-26.06; log rank $P=0.0004)$ three CTCs. The progression-free survival proportion was much lower $(20 \%)$ in the patients who had three or more CTCs than in patients who had less than three CTCs (81\%) (Fig. 1c).

Circulating tumor cells and overall survival

No significant difference in overall survival was observed between patients with one or more circulating tumor cell and patients with no CTCs using log-rank test $(P=0.09)$ and Cox proportional hazards analysis (hazard ratio $=2.36 ; 95 \% \mathrm{CI}, 0.84-6.65 ; P=0.12)$. Six $(26 \%)$ of twenty-three patients with one or more circulating tumor cell died compared with nine (13\%) of seventy-one patients with no CTCs. The overall survival proportion (70 \%) in the patients who had one or more circulating tumor cell did not differ significantly from that in patients who had no CTCs (86 \%) (Fig. 2a). However, a significant difference in overall survival proportion was observed between the patients who had two or more CTCs and the patients who had less than two CTCs using log-rank test $(P=0.0004)$ and Cox proportional hazards analysis (hazard ratio $=7.19 ; 95 \% \mathrm{CI}, 1.98-26.05 ; P=0.01$ ). Three $(50 \%)$ of six patients who had two or more CTCs died compared with twelve (14\%) of eighty-eight patients who had less than two CTCs. The overall survival proportion was much lower $(30 \%)$ in the patients who had two or more CTCs than in patients who had less than two CTCs $(85 \%)$ (Fig. 2b). Similarly, patients with three or more CTCs had lower overall survival rates than did patients with less than three CTCs using log-rank test $(P=0.0004)$ and Cox proportional hazards analysis (hazard ratio $=7.19 ; 95 \% \mathrm{CI}, 1.98-26.06 ; P=0.01$ ). Three $(60 \%)$ of five patients who had three or more CTCs died compared with twelve (13\%) of eighty-nine patients who had less than three CTCs. The overall survival proportion was much lower (30\%) in patients who had three or more CTCs than in patients who had less than three CTCs $(85 \%)$ (Fig. 2c).

Circulating tumor cells and primary tumor characteristics

We identified no significant correlation between circulating tumor cell presence and tumor size $(P=0.61)$, grade $(P=0.52)$, or Ki-67 status $(P=0.62)$

Circulating tumor cells and axillary lymph node status

We identified no significant correlation between circulating tumor cell presence and pathologic axillary lymph node status. This lack of significant association persisted after we stratified lymph node-positive patients into those with 
one to three or more than three positive lymph nodes $(P=0.55)$.

\section{Discussion}

This is one of the first reports demonstrating that the identification of two or more CTCs independently predicted both progression-free interval and overall survival in non-metastatic triple-negative breast cancer patients. Previously published studies included a smaller number of triple-negative patients [11, 13] or did not assess the prognostic significance of CTCs specifically for the triplenegative subtype $[13,19]$. In agreement with Kim et al. [20], we found that standard prognostic indicators such as $>2 \mathrm{~cm}$ tumor size and high tumor grade (Grade 3 ) did not often predict outcome in TNBC patients. Although tumor size and grade were not significantly associated with circulating tumor cell presence, we found that the identification of two or more CTCs demonstrated hazard ratios as prognostically powerful as $>3$ lymph node metastases for both relapse and death. These data suggest that circulating tumor cell assessment might provide additional prognostic information that could be useful in identifying TNBC patients who are at increased risk for disease progression.

We used the semi-automated CellSearch ${ }^{\circledR}$ platform for circulating tumor cell identification because it has been used in large clinical studies, it is standardized, and it is at present the only FDA-approved methodology for circulating tumor cell assessment (in metastatic breast, colorectal, and prostate cancer). Interestingly, one or more CTCs were identified in $20 \%$ of our patient cohort even though a majority had early-stage (69 \% had T1/T2 tumors) disease. The circulating tumor cell identification rate in this study is in agreement with the reported ranges (19-30\%) for patients with operable breast cancer in the GeparQuattro [21], REMAGUS 02 [12, 22], and SUCCESS-A trials [13], in a 2012 report by Franken et al. [19] and in 2012 and 2010 reports from our group [14, 17].

To date, circulating tumor cell information has not been used in the clinic to stage or guide management decisions for non-metastatic breast cancer patients. However, data are emerging about the prognostic significance of circulating tumor cell identification. The REMAGUS 02 [11, 19], SUCCESS-A trial [12], and our published report [13] demonstrated that the presence of one or more CTCs is an independent predictor of both progression-free and overall survival in patients with stages I-III breast cancer. In all of these studies, neither hormone receptor expression nor HER2 amplification status of the primary tumor predicted the presence of CTCs. Yet, hazard ratios associated with progression-free and overall survival in the presence of one or more circulating tumor cell were greater than hazard ratios observed associated with tumor size and grade, and presence of one or more circulating tumor cell was as prognostically powerful as lymph node metastasis. In the present study of patients with non-metastatic triple-negative breast cancer, the presence of one or more CTCs predicted shortened progression-free survival (mean progression-free interval, 12.3 months versus 27.7 months for patients with no circulating tumor cells, log-rank test $P=0.02$ ). The effect of one or more circulating tumor cell on overall survival did not reach significance (log-rank $P=0.09$ ), but the hazard ratio of 2.36 suggests a positive association. The lack of statistical significance is likely due to the small sample size, the low number of events, and the 40-month follow-up period used in the present study. We are continuing patient follow-up on our current protocol and are enrolling new TNBC patients to determine whether one or more circulating tumor cell predicted overall survival.

In this study, blood samples were obtained for circulating tumor cell analysis at the time of primary surgery, just before surgical resection. Just over half of the patients received NACT prior to circulating tumor cell assessment. We found no differences $(P=0.61)$ in circulating tumor cell identification rates between patients who were chemonaive and those who received NACT prior to circulating tumor cell analysis. These results are in agreement with several published reports demonstrating that CTCs can be identified in a significant number of patients following systemic neoadjuvant and adjuvant treatments regardless of the types of therapies employed. After neoadjuvant therapy, CTCs have been identified in 27-60\% of patients using polymerase chain reaction (PCR)-based methodologies [2327] and in 18-49 \% of patients using immunocytochemical methods [12, 13, 22, 28]. In all of these studies, the identification of CTCs after therapy predicted worse outcome. It is not surprising that CTCs are often identified in patients following cytotoxic therapies that targeted dividing cells, as CTCs have been reported to be dormant [29]. In addition, recent reports by Gazzaniga et al. have demonstrated that CTCs express multi-drug resistance proteins (MRPs) [30, 31]. Circulating tumor cell MRP expression independently predicted resistance to chemotherapy, and CTC MRP expression in metastatic breast cancer patients was associated with shortened progression-free survival. Therapies directed against biomarkers expressed in the primary tumor might also be ineffective against CTCs. For example, numerous recent reports indicate that HER2-positive CTCs can be identified in a significant number of patients with HER2 HER2-negative primary tumors [32-37]. Since therapy management is usually based solely upon primary tumor characteristics, these patients are not typically offered antiHER2 therapies. Given the aggressive nature of triple-negative breast cancer and the limited targeted therapy options 
available for these patients, circulating tumor cell identification and characterization are particularly important. Circulating tumor cell profiling might expedite the development of novel therapeutic agents that would benefit triple-negative patients who are at high risk for disease recurrence.

In the present study, the presence of one or more circulating tumor cell significantly predicted progression-free survival for patients with TNBC regardless of the presenting clinical stage of the disease. Although not statistically significant, the hazard ratio associated with one or more circulating tumor cell was as prognostically powerful as was $>2 \mathrm{~cm}$ primary tumor size and the presence of 1-3 lymph node metastases. Larger clinical studies are needed to determine the prognostic significance of one or more circulating tumor cell in triple-negative patients. In conjunction with ongoing research and published work, this study provides important insight into the prognostic significance of CTCs and establishes circulating tumor cell identification as an important research tool for future clinical studies investigating the development of therapeutic options for triple-negative patients.

Acknowledgments This work was supported by The Society of Surgical Oncology Clinical Investigator Award (A Lucci), by The Institute for Personalized Therapy at The University of Texas MD Anderson Cancer Center, and by and philanthropic funds.

Conflict of interest The authors declare no financial conflicts of interest.

Open Access This article is distributed under the terms of the Creative Commons Attribution Noncommercial License which permits any noncommercial use, distribution, and reproduction in any medium, provided the original author(s) and the source are credited.

\section{References}

1. Diaz LK, Cryns VL, Symmans WF, Sneige N (2007) Triple negative breast carcinoma and the basal phenotype: from expression profiling to clinical practice. Adv Anat Pathol 14(6):419-430. doi:10.1097/PAP.0b013e3181594733

2. Hugh J, Hanson J, Cheang MC, Nielsen TO, Perou CM, Dumontet C, Reed J, Krajewska M, Treilleux I, Rupin M, Magherini E, Mackey J, Martin M, Vogel C (2009) Breast cancer subtypes and response to docetaxel in node-positive breast cancer: use of an immunohistochemical definition in the BCIRG 001 trial. J Clin Oncol 27(8):1168-1176. doi:10.1200/JCO.2008.18.1024

3. Tischkowitz M, Brunet JS, Begin LR, Huntsman DG, Cheang MC, Akslen LA, Nielsen TO, Foulkes WD (2007) Use of immunohistochemical markers can refine prognosis in triple negative breast cancer. BMC Cancer 7:134

4. Dent R, Trudeau M, Pritchard KI, Hanna WM, Kahn HK, Sawka CA, Lickley LA, Rawlinson E, Sun P, Narod SA (2007) Triplenegative breast cancer: clinical features and patterns of recurrence. Clin Cancer Res 13(15 Pt 1):4429-4434. doi:10.1158/ 1078-0432.CCR-06-3045

5. Gabos Z, Thoms J, Ghosh S, Hanson J, Deschenes J, Sabri S, Abdulkarim B (2010) The association between biological subtype and locoregional recurrence in newly diagnosed breast cancer.
Breast Cancer Res Treat 124(1):187-194. doi:10.1007/s10549010-1135-1

6. Liedtke C, Mazouni C, Hess KR, Andre F, Tordai A, Mejia JA, Symmans WF, Gonzalez-Angulo AM, Hennessy B, Green M, Cristofanilli M, Hortobagyi GN, Pusztai L (2008) Response to neoadjuvant therapy and long-term survival in patients with triple-negative breast cancer. J Clin Oncol 26(8):1275-1281

7. Kennecke H, Yerushalmi R, Woods R, Cheang MC, Voduc D, Speers CH, Nielsen TO, Gelmon K (2010) Metastatic behavior of breast cancer subtypes. J Clin Oncol 28(20):3271-3277. doi:10. 1200/JCO.2009.25.9820

8. Dawood S, Broglio K, Esteva FJ, Yang W, Kau SW, Islam R, Albarracin C, Yu TK, Green M, Hortobagyi GN, GonzalezAngulo AM (2009) Survival among women with triple receptornegative breast cancer and brain metastases. Ann Oncol 20(4):621-627. doi:10.1093/annonc/mdn682

9. Fisher B, Anderson S, Bryant J, Margolese RG, Deutsch M, Fisher ER, Jeong JH, Wolmark N (2002) Twenty-year follow-up of a randomized trial comparing total mastectomy, lumpectomy, and lumpectomy plus irradiation for the treatment of invasive breast cancer. N Engl J Med 347(16):1233-1241

10. Wolmark N, Wang J, Mamounas E, Bryant J, Fisher B (2001) Preoperative chemotherapy in patients with operable breast cancer: nine-year results from national surgical adjuvant breast and bowel project B-18. J Natl Cancer Inst 30:96-102

11. Cristofanilli M, Budd GT, Ellis MJ, Stopeck A, Matera J, Miller MC, Reuben JM, Doyle GV, Allard WJ, Terstappen LW, Hayes DF (2004) Circulating tumor cells, disease progression, and survival in metastatic breast cancer. $N$ Engl $J$ Med 351(8):781-791. doi:10.1056/NEJMoa040766

12. Bidard FC, Mathiot C, Delaloge S, Brain E, Giachetti S, de Cremoux P, Marty M, Pierga JY (2010) Single circulating tumor cell detection and overall survival in nonmetastatic breast cancer. Ann Oncol 21(4):729-733. doi:10.1093/annonc/mdp391

13. Rack B, Schindlbeck C, Andergassen U, Lorenz R, Zwingers T, Schneeweiss A, et al. (2010) Prognostic relevance of circulating tumor cells in the peripheral blood of primary breast cancer patients. Paper presented at the San Antonio breast cancer symposium, San Antonio, TX

14. Lucci A, Hall CS, Lodhi AK, Bhattacharyya A, Anderson AE, Xiao L, Bedrosian I, Kuerer HM, Krishnamurthy S (2012) Circulating tumour cells in non-metastatic breast cancer: a prospective study. Lancet Oncol 13(7):688-695. doi:10.1016/S14702045(12)70209-7

15. Edge SB (2010) AJCC cancer staging manual, 7th edn. Springer, New York

16. Black MM, Speer FD (1957) Nuclear structure in cancer tissues. Surg Gynecol Obstet 105(1):97-102

17. Krishnamurthy S, Cristofanilli M, Singh B, Reuben J, Gao H, Cohen EN, Andreopoulou E, Hall CS, Lodhi A, Jackson S, Lucci A (2010) Detection of minimal residual disease in blood and bone marrow in early stage breast cancer. Cancer 116(14):3330-3337. doi: $10.1002 /$ cncr. 25145

18. McShane LM, Altman DG, Sauerbrei W, Taube SE, Gion M, Clark GM, Statistics Subcommittee of the NCIEWGoCD (2005) REporting recommendations for tumour MARKer prognostic studies (REMARK). Eur J Cancer 41(12):1690-1696. doi:10. 1016/j.ejca.2005.03.032

19. Franken B, de Groot MR, Mastboom WJ, Vermes I, van der Palen J, Tibbe AG, Terstappen LW (2012) Circulating tumor cells, disease recurrence and survival in newly diagnosed breast cancer. Breast Cancer Res 14(5):R133. doi:10.1186/bcr3333

20. Kim JE, Ahn HJ, Ahn JH, Yoon DH, Kim SB, Jung KH, Gong GY, Kim MJ, Son BH, Ahn SH (2012) Impact of triple-negative breast cancer phenotype on prognosis in patients with stage I 
breast cancer. J Breast Cancer 15(2):197-202. doi:10.4048/jbc. 2012.15.2.197

21. Muller V, Riethdorf S, Loibl S, Komor M, Houber J, Schrader I, Conrad U, Untch M, vMinckwitz G, Pantel K (2007) Prospective monitoring of circulating tumor cells in breast cancer patients treated with primary systemic therapy-A translational project of the German Breast Group study GeparQuattro. J Clin Oncol 25(18_suppl):21085

22. Pierga JY, Bidard FC, Mathiot C, Brain E, Delaloge S, Giachetti S, de Cremoux P, Salmon R, Vincent-Salomon A, Marty M (2008) Circulating tumor cell detection predicts early metastatic relapse after neoadjuvant chemotherapy in large operable and locally advanced breast cancer in a phase II randomized trial. Clin Cancer Res 14(21):7004-7010

23. Hwang SB, Bae JW, Lee HY, Kim HY (2012) Circulating tumor cells detected by RT-PCR for CK-20 before surgery indicate worse prognostic impact in triple-negative and HER2 subtype breast cancer. J Breast Cancer 15(1):34-42. doi:10.4048/jbc. 2012.15.1.34

24. Quintela-Fandino M, Lopez JM, Hitt R, Gamarra S, Jimeno A, Ayala R, Hornedo J, Guzman C, Gilsanz F, Cortes-Funes H (2006) Breast cancer-specific mRNA transcripts presence in peripheral blood after adjuvant chemotherapy predicts poor survival among high-risk breast cancer patients treated with highdose chemotherapy with peripheral blood stem cell support. J Clin Oncol 24(22):3611-3618. doi:10.1200/JCO.2005.04.0576

25. Saloustros E, Perraki M, Apostolaki S, Kallergi G, Xyrafas A, Kalbakis K, Agelaki S, Kalykaki A, Georgoulias V, Mavroudis D (2011) Cytokeratin-19 mRNA-positive circulating tumor cells during follow-up of patients with operable breast cancer: prognostic relevance for late relapse. Breast Cancer Res 13(3):R60. doi: $10.1186 /$ bcr 2897

26. Xenidis N, Ignatiadis M, Apostolaki S, Perraki M, Kalbakis K, Agelaki S, Stathopoulos EN, Chlouverakis G, Lianidou E, Kakolyris S, Georgoulias V, Mavroudis D (2009) Cytokeratin-19 mRNA-positive circulating tumor cells after adjuvant chemotherapy in patients with early breast cancer. J Clin Oncol 27(13):2177-2184. doi:10.1200/JCO.2008.18.0497

27. Yie SM, Luo B, Ye NY, Xie K, Ye SR (2006) Detection of survivin-expressing circulating cancer cells in the peripheral blood of breast cancer patients by a RT-PCR ELISA. Clin Exp Metastasis 23(5-6):279-289. doi:10.1007/s10585-006-9037-7

28. Wulfing P, Borchard J, Buerger H, Heidl S, Zanker KS, Kiesel L, Brandt B (2006) HER2-positive circulating tumor cells indicate poor clinical outcome in stage I to III breast cancer patients. Clin Cancer Res 12(6):1715-1720. doi:10.1158/1078-0432.CCR-052087

29. Muller V, Stahmann N, Riethdorf S, Rau T, Zabel T, Goetz A, Janicke F, Pantel K (2005) Circulating tumor cells in breast cancer: correlation to bone marrow micrometastases, heterogeneous response to systemic therapy and low proliferative activity.
Clin Cancer Res 11(10):3678-3685. doi:10.1158/1078-0432. CCR-04-2469

30. Gazzaniga P, Naso G, Gradilone A, Cortesi E, Gandini O, Gianni W, Fabbri MA, Vincenzi B, di Silverio F, Frati L, Agliano AM, Cristofanilli M (2010) Chemosensitivity profile assay of circulating cancer cells: prognostic and predictive value in epithelial tumors. Int J Cancer 126(10):2437-2447. doi:10.1002/ijc.24953

31. Gradilone A, Naso G, Raimondi C, Cortesi E, Gandini O, Vincenzi B, Saltarelli R, Chiapparino E, Spremberg F, Cristofanilli M, Frati L, Agliano AM, Gazzaniga P (2011) Circulating tumor cells (CTCs) in metastatic breast cancer (MBC): prognosis, drug resistance and phenotypic characterization. Ann Oncol 22(1):86-92

32. Apostolaki S, Perraki M, Pallis A, Bozionelou V, Agelaki S, Kanellou P, Kotsakis A, Politaki E, Kalbakis K, Kalykaki A, Vamvakas L, Georgoulias V, Mavroudis D (2007) Circulating HER2 mRNA-positive cells in the peripheral blood of patients with stage I and II breast cancer after the administration of adjuvant chemotherapy: evaluation of their clinical relevance. Ann Oncol 18(5):851-858. doi:10.1093/annonc/mdl502

33. Fehm T, Muller V, Aktas B, Janni W, Schneeweiss A, Stickeler E, Lattrich C, Lohberg CR, Solomayer E, Rack B, Riethdorf S, Klein C, Schindlbeck C, Brocker K, Kasimir-Bauer S, Wallwiener D, Pantel K (2010) HER2 status of circulating tumor cells in patients with metastatic breast cancer: a prospective, multicenter trial. Breast Cancer Res Treat 124(2):403-412. doi:10.1007/ s10549-010-1163-x

34. Ignatiadis M, Rothe F, Chaboteaux C, Durbecq V, Rouas G, Criscitiello C, Metallo J, Kheddoumi N, Singhal SK, Michiels S, Veys I, Rossari J, Larsimont D, Carly B, Pestrin M, Bessi S, Buxant F, Liebens F, Piccart M, Sotiriou C (2011) HER2-positive circulating tumor cells in breast cancer. PLoS ONE 6(1):e15624. doi:10.1371/journal.pone.0015624

35. Meng S, Tripathy D, Shete S, Ashfaq R, Haley B, Perkins S, Beitsch P, Khan A, Euhus D, Osborne C, Frenkel E, Hoover S, Leitch M, Clifford E, Vitetta E, Morrison L, Herlyn D, Terstappen LW, Fleming T, Fehm T, Tucker T, Lane N, Wang J, Uhr J (2004) HER-2 gene amplification can be acquired as breast cancer progresses. Proc Natl Acad Sci USA 101(25):9393-9398

36. Riethdorf S, Muller V, Zhang L, Rau T, Loibl S, Komor M, Roller M, Huober J, Fehm T, Schrader I, Hilfrich J, Holms F, Tesch H, Eidtmann H, Untch M, von Minckwitz G, Pantel K (2010) Detection and HER2 expression of circulating tumor cells: prospective monitoring in breast cancer patients treated in the neoadjuvant GeparQuattro trial. Clin Cancer Res 16(9): 2634-2645

37. Tewes M, Aktas B, Welt A, Mueller S, Hauch S, Kimmig R, Kasimir-Bauer S (2009) Molecular profiling and predictive value of circulating tumor cells in patients with metastatic breast cancer: an option for monitoring response to breast cancer related therapies. Breast Cancer Res Treat 115(3):581-590 